\title{
BMJ Open Primary care physician involvement during hospitalisation: a qualitative analysis of perspectives from frequently hospitalised patients
}

\author{
Erin Yildirim Rieger (D) , ${ }^{1}$ Josef N S Kushner, ${ }^{2}$ Veena Sriram (D) ${ }^{3}$ Abbie Klein (D) , ${ }^{4}$ \\ Lauren O Wiklund (D) , ${ }^{5}$ David O Meltzer (D) , ${ }^{4}$ Joyce W Tang (i) ${ }^{4}$
}

To cite: Rieger EY, Kushner JNS, Sriram V, et al. Primary care physician involvement during hospitalisation: a qualitative analysis of perspectives from frequently hospitalised patients. BMJ Open 2021;11:e053784. doi:10.1136/ bmjopen-2021-053784

- Prepublication history and additional supplemental material for this paper are available online. To view these files, please visit the journal online (http://dx.doi.org/10.1136/ bmjopen-2021-053784).

Received 25 May 2021 Accepted 12 November 2021

\section{Check for updates}

(c) Author(s) (or their employer(s)) 2021. Re-use permitted under CC BY-NC. No commercial re-use. See rights and permissions. Published by BMJ.

${ }^{1}$ Pritzker School of Medicine, University of Chicago, Chicago, Illinois, USA

${ }^{2}$ Department of Medicine, Lenox Hill Hospital, New York City, New York, USA

${ }^{3}$ School of Population and Public Health, The University of British Columbia, Vancouver, British

Columbia, Canada

${ }^{4}$ Department of Medicine, University of Chicago, Chicago, Illinois, USA

${ }^{5}$ Department of Psychology, Michigan State University, East Lansing, Michigan, USA

Correspondence to Dr Joyce W Tang; jtang@bsd.uchicago.edu

\section{ABSTRACT}

Objective To explore frequently hospitalised patients' experiences and preferences related to primary care physician (PCP) involvement during hospitalisation across two care models.

Design Qualitative study embedded within a randomised controlled trial. Semistructured interviews were conducted with patients. Transcripts were analysed using qualitative template analysis.

Setting In the Comprehensive Care Programme (CCP) Study, in Illinois, USA, Medicare patients at increased risk of hospitalisation are randomly assigned to: (1) care by a CCP physician who serves as a PCP across both inpatient and outpatient settings or (2) care by a PCP as outpatient and by hospitalists as inpatients (standard care).

Participants Twelve standard care and 12 CCP patients were interviewed.

Results Themes included: (1) Positive attitude towards PCP; (2) Longitudinal continuity with PCP valued; (3) Patient preference for PCP involvement in hospital care; (4) Potential for in-depth involvement of PCP during hospitalisation often unrealised (involvement rare in standard care; in CCP, frequent interaction with PCP fostered patient involvement in decision making); and (5) PCP collaboration with hospital-based providers frequently absent (no interaction for standard care patients; CCP patients emphasising PCP's role in interdisciplinary coordination).

Conclusion Frequently hospitalised patients value PCP involvement in the hospital setting. CCP patients highlighted how an established relationship with their PCP improved interdisciplinary coordination and engagement with decision making. Inpatient-outpatient relational continuity may be an important component of programmes for frequently hospitalised patients. Opportunities for enhancing PCP involvement during hospitalisation should be considered.

\section{INTRODUCTION}

Before the mid-1990s, primary care physicians (PCPs) in the USA typically oversaw care for their own patients when they were hospitalised. Since that time, the number of hospitalists has significantly increased within the USA. ${ }^{1}$ This shift in care delivery
Strengths and limitations of this study

- This study provided a unique context within a randomised controlled trial with one group of patients cared for by hospitalists and one group cared for by their primary care physician (PCP) during hospitalisation.

- This study's qualitative approach allowed for a rich exploration of patients' experiences and preferences related to PCP involvement in hospitalisation.

- Self-selection bias is a possible limitation-patients recruited for the embedded qualitative study may have been a healthier and more engaged group than the overall study population.

- This study was conducted at an academic medical centre; experiences of the standard care group reflect the context of receiving care from trainees.

model was motivated by perceptions about increased hospitalist efficiency, availability, specialised expertise, and possible cost and mortality reductions. ${ }^{12}$ Despite such advantages, the hospitalist model may increase fragmentation between inpatient and outpatient care, particularly for patients who are frequently hospitalised. ${ }^{1}$ Previous studies found that hospitalised patients frequently had limited knowledge about their diagnosis, care plan or postdischarge instructions. $^{3-5}$ Other studies identified discrepancies between hospitalised patients and their inpatient physicians in perceived goals of care, ${ }^{6}$ and limited opportunities for shared decision making. ${ }^{3} 78$ A possible contributing factor to these communication barriers is lack of an established relationship between hospitalised patients and their inpatient physicians. In comparison, PCPs with whom patients have ongoing relationships often have intimate knowledge of patients' preferred communication style, values, family context and care preferences, but 
infrequently communicate directly with patients during hospitalisation. ${ }^{9-11}$ Communication between PCPs and inpatient providers during hospitalisation may also be limited in frequency and scope. ${ }^{12} 13$

Particularly for patients with complex needs, PCP involvement during hospitalisation may greatly impact patient experience due to their familiarity with their patients' complex health history and established relationship with patients. However, few studies directly compare the hospitalisation experiences of patients cared for by their PCP versus by hospitalists. These are limited to quantitative comparisons related to satisfaction. ${ }^{14}{ }^{15}$ There is a need for qualitative patient perspectives on the role of a PCP in the hospital setting.

We conducted a qualitative study of frequently hospitalised patients' experiences and preferences related to PCP involvement during hospitalisation. This qualitative study was embedded within a larger randomised controlled trial, the Comprehensive Care Programme (CCP) Study. Patients at increased risk of hospitalisation are randomly assigned to one of two care models: (1) a CCP physician who serves as both the outpatient PCP and hospital attending (intervention arm) or (2) outpatient care from a PCP and hospital care from hospitalists (standard care) ${ }^{16}$ This study context provides a unique opportunity to explore and compare the experiences and preferences surrounding PCP involvement during hospitalisation between patients cared for by hospitalists as compared with a patient's own PCP.

\section{METHODS \\ Setting}

The CCP study at the University of Chicago Medicine (UCM) is a randomised controlled trial assessing the effect of an interdisciplinary care team for patients at high risk of hospitalisation. The overall CCP study recruited Medicare part A and B enrollees with at least one hospitalisation at UCM within the previous twelve months. Patients randomised to the intervention group were cared for by PCPs with limited panels of approximately 200 patients to enable them to care for their patients as the primary attending in both inpatient and outpatient settings. As outpatients, the patients also receive care from a social worker, two nurses and a clinic coordinator. Patients randomised to the control group received 'standard of care,' which included following with their prior PCP (or were offered assistance in obtaining one if they did not have one) and being treated by hospitalist physicians if admitted to UCM. ${ }^{16}$

The broader CCP study compares clinical outcomes, healthcare costs and experiences of patients in CCP versus standard care. ${ }^{16}$ This embedded study used qualitative interviews with a subset of both CCP and standard care patients to better understand and compare patients' experiences and preferences surrounding the role of their PCP during hospitalisation.

\section{Participant selection}

The participants for the embedded qualitative study were drawn from the broader CCP study. Additional inclusion criteria included, participation in the CCP study for at least 1 year, and having at least three hospitalisations within the previous twelve months (based on self-report during quarterly phone surveys), with the most recent hospitalisation occurring at UCM. For intervention group patients, medical records were screened to confirm that their assigned CCP physician served as their primary attending during the most recent hospitalisation. Patients were recruited by a research assistant or medical student in-person or by phone between July 2017 and August 2018. Recruitment continued until data saturation was reached.

\section{Development of interview guide}

The semistructured interview guide was developed by an interdisciplinary team including a CCP physician (JWT), a medical student without ties to CCP (JNSK), a CCP social worker (NG) and a research assistant without ties to CCP $(\mathrm{JH})$. Two members of the team (JWT, JH) had prior experience in qualitative research methods. The interview guide was further modified after review by three patients in the intervention arm of the CCP study. The final interview guide (online supplemental appendix A) focused on patients' care experiences during and after their most recent hospitalisation at UCM, with an emphasis on: (1) communication with physicians and nurses in the hospital setting, particularly surrounding goals of the hospitalisation and decision making; (2) postdischarge care and (3) relationship with their PCP and their PCP's role during hospitalisation.

\section{Data collection}

Semistructured interviews, approximately $30 \mathrm{~min}$ in length, were conducted in-person at UCM by a medical student and a research assistant, neither with ties to CCP (JNSK or AK). Patients provided verbal consent for the interview and received a US $\$ 30$ gift card for participation. All patients had previously provided written consent for the broader CCP study. Patient characteristics including sex, age and healthcare utilisation were collected from the medical record.

\section{Data analysis}

The interviews were digitally recorded and transcribed by the research team; identifiable personal data were redacted. The interview transcripts were analysed using template analysis, a methodology developed by Crabtree and Miller. ${ }^{17}$ Template analysis was selected as a systematic yet flexible methodology that lends itself to analysis across the two groups of subjects. The qualitative analysis team (JWT, EYR and JNSK) was composed of one CCP physician and two medical students. The three team members separately reviewed five interview transcripts (three control group; two CCP group) and engaged in discussions to develop a preliminary 'template' (coding 
guide), a hierarchical organisation of the identified themes. ${ }^{18}$ Some codes were identified inductively and others were rooted in the interview guide questions. Through an iterative process, additional codes were added to the template as they arose from the five sample transcripts. The three team members then applied the initial template to code the transcripts using NVivo V.11 (QRS International) software. Two coders reviewed each of the 24 transcripts. During analysis, the team met weekly to resolve discrepancies in coding through discussion and to revise the template. After the template was finalised, themes were developed through repeated review of codes and discussion. These themes were described, and representative quotes were selected and agreed on by the entire research team. The qualitative analysis team practised reflexivity through open communication about their preconceptions and how their roles in patient care relate to their perspective. ${ }^{19}$

\section{Patient and public involvement}

Three CCP patients provided feedback on the interview guide during development. As a check on the validity of the analysis, results were reviewed and discussed with the CCP study patient and community advisory board and with CCP physicians, team members and administrators.

\section{RESULTS}

\section{Patient sample}

Twenty-four interviews were conducted, 12 with CCP patients and 12 with standard care patients. Patient characteristics are shown in table 1.

For CCP and standard care groups combined, 50\% were female and the average age was 53 years. Patients had been enrolled in the CCP study for an average of 2.7 years at the time of interview. All patients had two or more chronic medical conditions. Of the standard care patients, $67 \%$ received primary care from internal medicine resident physicians; all CCP patients were cared for by attending physicians.

\section{Theme 1: positive attitude towards PCP}

Themes and additional quotes from interviews are summarised in table 2.

\section{Patient is comfortable talking with their PCP}

A majority of CCP patients and a few standard care patients described feeling comfortable conversing with their PCP. Patients in both groups valued that their PCP listened to what they said. Several CCP patients, but only a few of the standard care patients, thought discussions were better with their PCP than with hospital providers. A common perception was that the patient could speak more openly with their PCP.

It's good because I can openly talk to him and not be afraid to tell him if something is not going right.

(Female, standard care)

Several CCP patients also described engaging with their PCP about topics outside of medicine, including challenging social issues.

You want to be straight up with your primary about things. You want to tell him everything, what's giving you problems. Well my wounds are giving me problems, do you have any other issues? And you tell him: well depression issues, housing issues. (Male, CCP)

Table 1 Participant characteristics

\begin{tabular}{|c|c|c|c|}
\hline Characteristics & $\begin{array}{l}\text { All patients } \\
(n=24)\end{array}$ & $\begin{array}{l}\text { Standard care patients } \\
(n=12)\end{array}$ & $\begin{array}{l}\text { CCP patients } \\
(n=12)\end{array}$ \\
\hline Age in years* (mean (SD)) & $53(14)$ & $57(15)$ & $49(11)$ \\
\hline Years since CCP study enrolment* (mean (SD)) & $2.7(1.2)$ & $2.7(1.3)$ & $2.7(1.1)$ \\
\hline \multicolumn{4}{|c|}{ Chronic medical conditions (n (\%)) } \\
\hline Diabetes & $11(46)$ & $7(58)$ & $4(33)$ \\
\hline End-stage renal disease & $10(42)$ & $5(42)$ & $5(42)$ \\
\hline Chronic lung disease $†$ & $8(33)$ & $7(58)$ & $1(8)$ \\
\hline Cancer & $2(8)$ & $1(8)$ & $1(8)$ \\
\hline
\end{tabular}

${ }^{*}$ At time of interview.

†Chronic obstructive pulmonary disease, Asthma, Interstitial lung disease, Pulmonary arterial hypertension, Cystic fibrosis. ¥Scleroderma, Crohn's disease.

§Sickle cell disease, Spina bifida.

CCP, Comprehensive Care Programme. 
Table 2 Themes and exemplary quotes across standard care and CCP groups

Theme Standard care patients $(n=12) \quad$ CCP patients $(n=12)$

1. Positive attitude Valued comfort communicating with PCP, and PCP compassion. CCP patients additionally reported shared trust. towards PCP I was able to talk with [PCP], he was able to talk with me, and we were comfortable speaking with each other...I'm going through this, and he's like: 'I understand what you're going through, we're going to do this, this, and this.' (Male, standard care)

... [PCP] lets me know that 'everything's going to be okay, I've got you. If there's anything you need, if you feel like you have any problems, just let me know.'... you need that on your team sometimes. (Male, CCP)

2. Longitudinal Experienced frequent turnover of continuity with PCP PCP valued

I usually prefer not to see the
Described longitudinal relationships with their PCP which improved over time

We've known each other a little while now, because I was going through residents...I've got a long life-history as far as medical stuff, and if I have to go through it every two years it's not worth it to me. (Female, standard care)

$\begin{array}{ll}\begin{array}{l}\text { 3. Patient } \\ \text { preference for PCP }\end{array} & \text { Majority preferred some contact } \\ \text { involvement in } & \text { I think the team should go back to } \\ \text { hospital care } & \text { the primary care and say: 'This is } \\ & \begin{array}{l}\text { what we're doing. Do you have any } \\ \text { suggestions for us?' Because they } \\ \text { know your health better than the } \\ \text { new people. (Male, standard care) }\end{array}\end{array}$

4. Potential for indepth involvement of PCP during hospitalisation often unrealised

\section{PCP}

collaboration with hospitalbased providers frequently absent
Most did not interact with their PCP during hospitalisation

Check on me, talk to me, say something. But they don't. (Male, standard care)

Most were not aware of interaction between PCP and hospital providers No particular role... while I'm in the hospital, [the PCP] can communicate with doctors if they needed to communicate with him. (Female, standard care) doctors: some come some go. But I've been with Dr. PCP here for a minute now, so I try to assess everything I can do. Let her know everything about me, so I won't be uncomfortable with her and she won't be uncomfortable with me. So when I do get in a situation like I'm hurting, I'm in pain, my anxiety, she'll know straight up what's going on. She can assess it right then and there the best way she can. (Male, CCP)

Preferred inpatient treatment by PCP due to shared trust and their prior knowledge of the patient

...it's just a comfortable feeling... When I'm admitted into the hospital I feel like they're my security. You get what I'm saying? Like they have my back. If something goes wrong, even if they're not there in the moment, it's only a matter of time before they get there and whatever's the issue, I know I'm going to be treated fairly. (Female, CCP)

Described active involvement of their PCP in decision-making I took(the PCP's)advice and took the option that she give first as opposed to plan B, plan $C$, whatever, because she informed me and worked with me and knows my health and how the medication will affect me and what I need to do. (Male, CCP)

Emphasised PCP's role aligning the knowledge and goals of various providers

The people when you come into the hospital: they don't know you...It takes Dr. PCP and the doctors to get together and communicate with each other. Because he knows me and he knows what I went through-and he went through all that with me-he can communicate with the doctors and tell the doctors about me. With what he knows and what we've been dealing with with my medications...they can give me the better care. (Female, CCP)

CCP, Comprehensive Care Programme; PCP, primary care physician.

PCP is caring towards patient

Across CCP and standard care, several patients expressed that they felt cared for by their PCP. Patients appreciated that the PCP was concerned about their health and that the physician offered their time and attention.

She sits and talks to me, she [...] connects with me, you know. Not just like business type thing, but a family type thing. (Male, CCP)

\section{Shared trust between patient and PCP}

Half of CCP patients, but none of the standard care patients, mentioned shared trust with their PCP. In several instances, CCP patients stated that their PCP trusted them to make their own decisions about care. Participants also described an increased level of trust in their CCP's judgement over time.

See we have this really good relationship, and she knows that I am an informed patient. I know my body and I can pretty much tell her more than she can tell me about my body, and so she trusts me the same way I trust her. (Female, CCP)

\section{Theme 2: longitudinal continuity with PCP valued}

Many standard care and CCP patients emphasised that it takes time to build a relationship with a PCP. A majority of standard care participants described discontinuity with their PCPs. A few patients attributed the frequent changes to receiving primary care from residents who graduated and transitioned their patients to new trainees.

[...] this'll be my 4th primary care doctor in 10 years. But, you know, you guys do your 2 or 3 year residency, then you're off [...] But at some point you've got to learn, like what you're doing with me. (Male, standard care)

In comparison, CCP patients experienced greater relational continuity with their physician. A majority of CCP 
patients mentioned that the relationship with their CCP physician improved over time as they got to know each other. Two participants described a difficult start that morphed into a positive relationship.

Once you get to know a person it gets better because you know the first couple of times it's not going to be smooth sailing. (Male, CCP)

\section{Theme 3: patient preference for PCP involvement in hospital care}

A majority of standard care patients and nearly all CCP patients stated that their PCP should be involved during hospitalisation. However, there was variation in the preferred form of involvement. A majority of standard care patients thought that ideally a PCP would remain in communication with their patient during hospitalisation.

It shows they care, they're concerned about my being, my health. And that's a good thing. (Female, standard care)

Patients commonly preferred that this interaction be in person, with a few specifically stating that they would prefer to be treated by their PCP while in the hospital. A few standard care patients noted that their PCP could have been able to offer emotional support during hospitalisation.

[...] he probably could have informed me and let me know more about what was going on, and I would have had less anxiety. I would have felt more relieved. (Male, standard care)

Further, a few standard care patients thought that a PCP should remain in communication with the patient's care team during hospitalisation. PCP involvement was considered beneficial due to their prior knowledge of the patient's health conditions.

I don't think he should just be in the office all the time. I think he should know about me being in the hospital and why and help me to maintain my health. I mean, these other doctors, they don't really see me that much. They don't know much about me. They just know what I come in and I complain about, and then they fix that and then they send me on my way? What if I have another issue that they're not aware of that my primary care doctor is aware of? (Female, standard care)

On the other hand, some standard care patients stated that they chose not to reach out to their PCP during hospitalisation due to lack of a relationship with their PCP. Others shared that they had no expectation of PCP involvement during hospitalisation. These patients thought it was sufficient for the PCP to view records following discharge or answer questions if contacted by the hospital team.

I just concentrate on the doctors at hand, and I know that they're making notes so he see it on the chart. I don't have it where I can text him and let him know each time I'm in the hospital [...] So, by the time I see him, I'm quite sure there's a flag somewhere to let him know I've been in the hospital, and he can read the chart and see that I've been in the hospital so.

(Female, standard care)

Among CCP patients, all described a preference to be treated by their PCP in the hospital setting. For several, a PCP's knowledge about their health and personal preferences was thought to expedite care and improve adherence to previously developed plans.

Besides my opinion, she should be able to make the decision. She should be the one running stuff. Should no other doctor be running nothing or make no decisions because you don't know me. (Female, CCP)

A few CCP patients also pointed to the shared trust with their PCP. Due to previous hospitalisations or office visits patients perceived that the PCP had greater understanding of the patient's preferences, and the patient felt comfortable with the PCP's plan.

[...] I feel like with any other doctor, it would be like: 'You were just ready to go home, now all of a sudden I say this and you're not feeling well.' I think she knows that it's not just necessary that I'm not saying I'm not feeling well, I think she knows what I've told her already, why I like the blood transfusions, so she don't look at it like a ploy. (Female, CCP)

\section{Theme 4: potential for in-depth involvement of PCP during hospitalisation often unrealised}

There was considerable variation between the two groups in interaction between the patient and PCP during hospitalisation. Most standard care patients did not interact with their PCP during hospitalisation.

He usually gets the report after I'm out [...] I just go through whatever doctor sees me in the emergency room, and then they send to the floor. (Female, standard care)

For the few patients who described interaction, some initiated, and some were contacted by their PCP. The form of PCP-patient interaction also varied. A few patients received in person-visits from their $\mathrm{PCP}$ and one talked with their PCP over the phone. Patients expressed positive feelings towards their PCP visiting them in the hospital. However, there was little elaboration about how and to what extent the PCP actively participated in their care during hospitalisation.

For CCP patients, nearly all described frequent in-person interaction with their PCP during hospitalisation. Most patients discussed their plan of care with the PCP. Half described making decisions with their PCP about treatment options or the timing of discharge.

Mainly I talked to my Comprehensive doctor. She's like the main authority over all of that. They have 
to talk to her first, you know to see if I'm okay with leaving. She'll come ask me: 'How do you feel about leaving today?' If I say 'I don't feel like leaving,' she'll be like: 'You can stay an extra day,' [...] (Male, CCP)

\section{Theme 5: PCP collaboration with hospital-based providers frequently absent}

There was also significant variation between the two groups in experience of interaction between the PCP and hospital providers. Only two standard care patients described being aware of interaction between their PCP and hospital providers, such as providing guidance to the inpatient care team. A few standard care patients openly expressed uncertainty and concern about whether their PCP was contacted during their hospitalisation.

I don't know for sure that they're calling him and letting him know or if he's getting the reports or any of that. I need to know that he's getting this information to know I'm there. (Female, standard care)

Among CCP patients, a majority described their PCP being in communication with other hospital providers. Several of these patients referred to the PCP as leader of their healthcare team in the hospital. Patients described their PCPs keeping specialists informed and interfacing with the other providers when the patient had a concern or conflict.

She's my main doctor, so she makes sure everybody gets the email when I'm in the hospital. They'll know that: 'OK I gotta go see how he's doing, and see if I can give him any help for his pain or anything.' So that's the best thing I can ask for. That's probably why I switched from another hospital. Since I can just ask my Comprehensive Care anything wrong with me, she'll make sure that all my other doctors know too, so I ain't gotta be worrying about it, like my pain, or if I miss an appointment they'll all be informed that I'm in the hospital [...] (Male, CCP)

\section{DISCUSSION}

The main aim of this study was to explore frequently hospitalised patients' experiences and preferences related to PCP involvement during hospitalisation. A unique contribution of this study was the qualitative comparison of perspectives of standard care patients who were cared for by hospitalists or housestaff teams to those of CCP patients being treated by their own PCP during hospitalisation.

Both standard care and CCP patients expressed a preference for repeated interactions with their PCP over time to build a relationship and shared knowledge. While CCP patients described consistent relationships with their PCPs that benefited from shared experiences across inpatient and outpatient settings, many standard care patients described relational discontinuity with PCPs, which sometimes weakened these relationships. These results were consistent with prior research that patients prefer, and may benefit from, relational continuity of care with physicians, ${ }^{20-23}$ and that patients' trust in their PCP was associated with the duration of their relationship. ${ }^{24}$

It is concerning that in this study of patients with frequent hospitalisation and multiple chronic conditions, many in standard care may not experience the benefits of long-term relational continuity. Most of the patients experiencing discontinuity received care in a resident clinic characterised by frequent turnover. It is possible that the purposive sampling of this embedded qualitative study disproportionately selected for standard care patients with resident PCPs. Unfortunately, these patients' experiences with PCP discontinuity are not unique. Previous studies found that, as compared with patients with attending PCPs, patients with resident PCPs were more likely to have multiple health conditions, and be non-white, of low socioeconomic status, and on Medicare or Medicaid insurance. ${ }^{25-29}$ Patients who transition care to a new resident reported challenges including missed tests and difficulty building a relationship with a new provider. ${ }^{30}$ Patients may also experience PCP discontinuity due to the resident clinic schedule. ${ }^{31}$

A vast majority of patients in this study wanted their PCP to be involved during hospitalisation, a preference consistent with previous findings. ${ }^{932}$ Despite the overall preference for PCP involvement during hospitalisation, few standard care patients described actual involvement of their PCP during hospitalisation; when involved, the PCP role was usually limited to single visits or brief conversations with the patient or hospital providers. The finding that a majority of the standard care patients did not have interaction with their PCPs during hospitalisation echoes previous research. ${ }^{9}{ }^{10}$

In contrast, consistent with the structure of the programme, CCP patients described substantial involvement of their PCPs during hospitalisation. A major contribution of this study was in highlighting the value of PCP involvement in the hospital setting through the lens of patients in CCP. Specifically, patients in CCP emphasised the PCP's role as a leader of their care team. Patients found it reassuring to have their PCP working to align the knowledge and goals of the various hospital providers. CCP patients expressed that shared trust with their PCP allowed for more patient involvement in care decisions due to greater patient comfort to voice disagreement, and PCP respect for the patient's input. As the CCP model is further developed and disseminated to other care settings, longitudinal relationships and direct patient engagement in the inpatient setting will be important components to uphold.

Inpatient-outpatient relational continuity is a component of other interdisciplinary programmes for frequently hospitalised patients. The nature of team involvement in the inpatient setting varies. For instance, the University of Colorado intensive outpatient clinic team collaborates with hospital providers to develop care plans. ${ }^{33}$ In 
the CareMore Health System, hospitalists treat high-risk patients for a limited duration across the transition from inpatient to rehabilitation or community settings. ${ }^{34}$ Social workers in the Northwestern University Complex High Admission Management Programme provide continuity by rounding on their admitted patients. ${ }^{35}$ It is unknown if and to what extent findings from this CCP study may translate to programmes with inpatient-outpatient continuity involving a non-PCP provider, or inpatient involvement that is not direct care. Incorporating patient perceptions into evaluation plans for these interdisciplinary programmes could refine our understanding of the nature of involvement needed.

In practice, it is uncommon for patients in the USA to be treated by their PCP while hospitalised. In a sample of 2013 Medicare data, PCPs cared for their own patient in only $14.2 \%$ of hospital admissions. ${ }^{36}$ However, for frequently hospitalised patients, increasing PCP engagement in the inpatient setting may improve patient experiences, even if the PCP is not providing direct care. PCPs can use their relationship with the patient to help assess preferences and identify needs. This may benefit the patient by encouraging patient engagement in decisionmaking, strengthening the patient-PCP relationship, and improving interdisciplinary coordination across settings. To achieve this, a first challenge is ensuring that PCPs receive information when their patient is hospitalised. ${ }^{37}$ Healthcare systems may also consider how to provide PCPs with time and compensation for communicating with their hospitalised patients and their inpatient care teams by phone or in-person visit. ${ }^{38}$

There are several limitations of the patient sample and analysis. First, patients recruited for the embedded qualitative study may have been a healthier and more engaged group than the overall study population. In the case of CCP patients, those with positive feelings towards the programme may have been most likely to participate. Second, while all CCP patients had attending physicians as PCPs, $67 \%$ of the standard care patients had resident physicians as PCPs. Although a limitation, it also reflects the reality that complex, vulnerable, patients who experience frequent hospitalisations often receive primary care from residents. Third, the exclusive focus on PCPs in the analysis is a limitation. CCP PCPs may share similar roles or characteristics with specialists or other providers who see patients across care settings.

\section{CONCLUSION}

In summary, this study was a valuable contribution to the existing literature on PCP involvement during hospitalisation due to the qualitative comparison of perspectives of standard care and CCP patients. Specifically, the results suggested that for frequently hospitalised patients, active inpatient involvement by a consistent PCP with knowledge of the patient's health and personal preferences could improve patient experience with interdisciplinary coordination and engagement in care during hospitalisation.
For frequently hospitalised patients not being treated in the hospital by their PCP, future research is needed to clarify which forms of PCP engagement may be most likely to confer these benefits.

Twitter Erin Yildirim Rieger @erinyrieger, Veena Sriram @veena_sriram and Joyce W Tang @joycewtang

Acknowledgements Thank you to the patients interviewed in the study for their time and willingness to discuss their medical care. Thank you to Nicole Gier and Jannelle Highland for their assistance with developing the interview guide. Thank you also to Andrea Flores, MA for her role in developing the sampling approach used in this study.

Contributors EYR: formal analysis, writing—original Draft. JNSK: methodology, formal analysis, investigation, writing —original Draft. VS: methodology, writing — review and editing. AK: investigation, writing — review and editing. LOW: methodology, writing — review \& editing. DOM: conceptualisation, writing — review and editing, funding acquisition. JWT: conceptualisation, methodology, formal analysis, writing —original draft, supervision, guarantor.

Funding This work was supported by: Centers for Medicare and Medicaid Services, Center for Medicare and Medicaid Innovation grant CMS-1C1-12- 0001; Agency for Healthcare Research and Quality, Patient Centered Outcomes Research Faculty Development Program grant K12; and National Institutes of Health, National Institute on Aging grant 5T35AG029795-12.

Competing interests None declared.

Patient consent for publication Not applicable.

Ethics approval This study received approval from the University of Chicago Institutional Review Board (IRB12-1440).

Provenance and peer review Not commissioned; externally peer reviewed.

Data availability statement Data are available on reasonable request. Full transcripts have not been shared to protect anonymity of patients.

Supplemental material This content has been supplied by the author(s). It has not been vetted by BMJ Publishing Group Limited (BMJ) and may not have been peer-reviewed. Any opinions or recommendations discussed are solely those of the author(s) and are not endorsed by BMJ. BMJ disclaims all liability and responsibility arising from any reliance placed on the content. Where the content includes any translated material, BMJ does not warrant the accuracy and reliability of the translations (including but not limited to local regulations, clinical guidelines, terminology, drug names and drug dosages), and is not responsible for any error and/or omissions arising from translation and adaptation or otherwise.

Open access This is an open access article distributed in accordance with the Creative Commons Attribution Non Commercial (CC BY-NC 4.0) license, which permits others to distribute, remix, adapt, build upon this work non-commercially, and license their derivative works on different terms, provided the original work is properly cited, appropriate credit is given, any changes made indicated, and the use is non-commercial. See: http://creativecommons.org/licenses/by-nc/4.0/.

\section{ORCID iDs}

Erin Yildirim Rieger http://orcid.org/0000-0002-0888-5056

Veena Sriram http://orcid.org/0000-0001-7235-253X

Abbie Klein http://orcid.org/0000-0002-1077-1269

Lauren 0 Wiklund http://orcid.org/0000-0001-9997-0813

David 0 Meltzer http://orcid.org/0000-0002-6728-8729

Joyce W Tang http://orcid.org/0000-0003-4792-924X

\section{REFERENCES}

1 Wachter RM, Goldman L. The hospitalist movement 5 years later. JAMA 2002;287:487-94.

2 Meltzer D, Manning WG, Morrison J, et al. Effects of physician experience on costs and outcomes on an academic general medicine service: results of a trial of hospitalists. Ann Intern Med 2002;137:866-74.

3 Berger ZD, Boss EF, Beach MC. Communication behaviors and patient autonomy in hospital care: a qualitative study. Patient Educ Couns 2017;100:1473-81.

4 Calkins DR, Davis RB, Reiley P, et al. Patient-physician communication at hospital discharge and patients' understanding 
of the postdischarge treatment plan. Arch Intern Med 1997;157:1026-30.

5 Olson DP, Windish DM. Communication discrepancies between physicians and hospitalized patients. Arch Intern Med 2010;170:1302-7.

6 Figueroa JF, Schnipper JL, McNally K, et al. How often are hospitalized patients and providers on the same page with regard to the patient's primary recovery goal for hospitalization? J Hosp Med 2016;11:615-9.

7 Storm M, Davidson L. Inpatients' and providers' experiences with user involvement in inpatient care. Psychiatr Q 2010;81:111-25.

8 Apker J, Baker M, Shank S, et al. Optimizing hospitalist-patient communication: an observation study of medical encounter quality. Jt Comm J Qual Patient Saf 2018;44:196-203.

9 Hruby M, Pantilat SZ, Lo B. How do patients view the role of the primary care physician in inpatient care? Am J Med 2001;111:21-5.

10 Huang KB, Weber U, Johnson J, et al. Primary care physician involvement in shared decision making for critically ill patients and family satisfaction with care. J Am Board Fam Med 2018;31:64-72.

11 Brener SS, Bronksill SE, Comrie R, et al. Association between in-hospital supportive visits by primary care physicians and patient outcomes: a population-based cohort study. J Hosp Med 2016;11:418-24.

12 Adams DR, Flores A, Coltri A, et al. A missed opportunity to improve patient satisfaction? patient perceptions of inpatient communication with their primary care physician. Am J Med Qual 2016;31:568-76.

13 Kripalani S, LeFevre F, Phillips CO, et al. Deficits in communication and information transfer between hospital-based and primary care physicians: implications for patient safety and continuity of care. JAMA 2007;297:831-41.

14 Seiler A, Visintainer P, Brzostek R, et al. Patient satisfaction with hospital care provided by hospitalists and primary care physicians. J Hosp Med 2012;7:131-6.

15 Chen LM, Birkmeyer JD, Saint S. Hospitalist staffing and patient satisfaction in the National Medicare population: hospitalist care and patient satisfaction. J Hosp Med 2013;8:126-31.

16 Meltzer DO, Ruhnke GW. Redesigning care for patients at increased hospitalization risk: the comprehensive care physician model. Health Aff 2014;33:770-7.

17 Crabtree BF, Miller WF. A template approach to text analysis: Developing and using codebooks. In: Crabtree BF, Miller WF, eds. Doing qualitative research. Thousand Oaks, CA: Sage Publications, 1992: 93-109.

18 King N, Analysis T. A template approach to text analysis: developing and using codebooks. In: Simon G, Cassell C, eds. Qualitative methods and analysis in organizational research: a practical guide. Thousand Oaks, CA: Sage Publications, 1998: 118-34.

19 Malterud K. Qualitative research: standards, challenges, and guidelines. Lancet 2001;358:483-8.

20 Aboulghate A, Abel G, Elliott MN, et al. Do English patients want continuity of care, and do they receive it? Br J Gen Pract 2012;62:e567-75.
21 Waibel S, Henao D, Aller M-B, et al. What do we know about patients' perceptions of continuity of care? A meta-synthesis of qualitative studies. Int J Qual Health Care 2012;24:39-48.

22 Bayliss EA, Ellis JL, Shoup JA, et al. Effect of continuity of care on hospital utilization for seniors with multiple medical conditions in an integrated health care system. Ann Fam Med 2015;13:123-9.

23 Pereira Gray DJ, Sidaway-Lee K, White E, et al. Continuity of care with doctors - a matter of life and death? A systematic review of continuity of care and mortality. BMJ Open 2018;8:e021161.

24 Mainous AG, Baker R, Love MM, et al. Continuity of care and trust in one's physician: evidence from primary care in the United States and the United Kingdom. Fam Med 2001;33:22-7.

25 Doctoroff L, McNally D, Vanka A, et al. Inpatient-outpatient transitions for patients with resident primary care physicians: access and readmission. Am J Med 2014;127:886.e15-20.

26 Zallman L, Ma J, Xiao L, et al. Quality of US primary care delivered by resident and staff physicians. J Gen Intern Med 2010;25:1193-7.

27 Yancy WS, Macpherson DS, Hanusa BH, et al. Patient satisfaction in resident and attending ambulatory care clinics. J Gen Intern Med 2001;16:755-62.

28 Charlson ME, Karnik J, Wong M, et al. Does experience matter? A comparison of the practice of attendings and residents. J Gen Intern Med 2005;20:497-503.

29 Essien UR, He W, Ray A, et al. Disparities in quality of primary care by resident and staff physicians: is there a conflict between training and equity? J Gen Intern Med 2019;34:1184-91.

30 Pincavage AT, Lee WW, Beiting KJ, et al. What do patients think about year-end resident continuity clinic handoffs? A qualitative study. J Gen Intern Med 2013;28:999-1007.

31 Wieland ML, Jaeger TM, Bundrick JB, et al. Resident physician perspectives on outpatient continuity of care. J Grad Med Educ 2013;5:668-73.

32 Shoeb M, Merel SE, Jackson MB, et al. "Can we just stop and talk?" patients value verbal communication about discharge care plans. J Hosp Med 2012;7:504-7.

33 Durfee J, Johnson T, Batal $\mathrm{H}$, et al. The impact of tailored intervention services on charges and mortality for adult super-utilizers. Healthc 2018;6:253-8.

34 Powers BW, Milstein A, Jain SH. Delivery models for high-risk older patients: back to the future? JAMA 2016;315:23

35 Theodorou ME, Henschen BL, Chapman M. The comprehensive care plan: a patient-centered, multidisciplinary communication tool for frequently hospitalized patients. Jt Comm J Qual Patient Saf 2020;46:217-26.

36 Stevens JP, Nyweide DJ, Maresh S, et al. Comparison of hospital resource use and outcomes among hospitalists, primary care physicians, and other generalists. JAMA Intern Med 2017;177:1781-7.

37 Jones CD, Vu MB, O'Donnell CM, et al. A failure to communicate: a qualitative exploration of care coordination between hospitalists and primary care providers around patient hospitalizations. J Gen Intern Med 2015;30:417-24.

38 Goroll AH, Hunt DP. Bridging the hospitalist-primary care divide through collaborative care. N Engl J Med 2015;372:308-9. 